\title{
The Application and Strategies of Schema in College English Reading Teaching
}

\author{
Meng-yuan CHEN \\ Shaanxi University of Traditional Chinese Medicine, Xianyang, Shaanxi, China
}

Keywords: Schema; College English Reading Teaching; Application.

\begin{abstract}
As it is known to all, English reading is an indispensable part in English teaching. Hence, enhancing students' reading comprehension capacity is becoming increasingly urgent. Different from traditional teaching methods, schema is a significant conception in cognitive psychology, including three types of schema, language schema, content schema and form schema. This paper briefly discusses the application in college English reading teaching respectively. What is more, strategies to motivate schema in college English reading classes are explained.
\end{abstract}

\section{The Application of Language Schema in College English Reading Teaching}

Language schema mainly refers to students' language knowledge about the reading texts, such as basic vocabulary, phrases and sentences, as well as some grammatical knowledge. There is no doubt that language schema is definitely basic in reading comprehension. Hence, students who are deficient in language schema probably have great difficulty in comprehending the given reading materials.

Taking some sentences appeared in a reading passage in New Horizon College English as examples: Americans believe no one stands still. If you are not moving ahead, you are falling behind. This attitude results in a nation of people committed to researching, experimenting and exploring.

To be honest, a great number of students can hardly comprehend the last sentence. For one reason, some students may have difficulty in distinguishing the phrases 'result in' and 'result from', which can be a great obstacle for interpreting this sentence. For another, being unfamiliar with another phrase 'be committed to' can also inevitably cause negative influence on comprehending this given sentence. When teaching reading in college English classes, apart from encouraging students to read extensively, teachers are also supposed to help establish efficient language schema for students, by enlarging students' basic vocabulary, imparting necessary phrases and sentences, as well as illustrating specific grammar. What is worth mentioning is that all these language items can be imparted in specific language context. Of course, some effective learning strategies can be imparted to students as well. For instance, associative strategy is greatly useful to enhance students' language level for students to learn and consolidate language items effectively. In one word, effective application of language schema plays a positive role in reading comprehension.

\section{The Application of Content Schema in College English Reading Teaching}

Content schema principally refers to the background knowledge previously possessed by students. Content schema can play active part in three reading phases: pre-reading, while-reading as well as post- reading.

\subsection{Pre-reading Phase}

Prediction in learning is an extremely useful tool. Actually, prediction is employed more widely in pre-reading process, as it is beneficial to help students figure out the main idea of the text more easily to some extent no matter it is right or wrong.

In pre-reading phase, the major objective of teachers is to help students make full reading preparation. In other words, background information related to the text such as information about the author, information about the cultural background existing in the text as well as some basic 
language items is supposed to be fully illustrated. In addition, although language schema is the prerequisite for reading comprehension, students who possess a certain basic language items still possibly fails to comprehend the given text if they are lack of efficient reading-related background information.

\subsection{While-reading Phase}

While-reading phase is the main phase comprehending the given text. The function of schema in this phase is information-processing. A certain number of schema related to background information has been activated in pre-reading phase, which can contribute to getting the general idea of the text. After that, the detailed information related to the text is to be specifically extended to the previous schema framework in this phase so that students can have a good master of the main idea of the text. In other words, both specific language knowledge and detailed content of the text are supposed to be illustrated at full length in this phase. In this way, reading comprehension can be mostly achieved.

\subsection{Post-reading Phase}

Schema's role in post-reading phase is consolidating reading comprehension and extending knowledge learned to other reading materials. That is, schema can contribute greatly to establishing a sound memory of the information conveyed in the given reading materials in a well- organized way. In the meantime, it can enable students to interpret the ingredients that they have not learned before as well as reconstruct those components they have forgotten.

\section{The Application of Form Schema in College English Reading Teaching}

Form schema can play a positive part considerably in reading comprehension. Different types of passage differ greatly in writing methods and forms. Distinct from traditional teaching methods which lay much emphasis on comprehending the text word by word, sentence by sentence, English text forms in different writing styles are suggested to be illustrated to students. The reason is that if students are possessed with abundant form schema, which is often considered as the knowledge about passage structures, they can easily figure out the logical relationship among each paragraph and further grasp what the authors are writing about.

When teaching reading, teachers are supposed to analyze the text structure specifically and impart considerable reading skills of this writing form to students in every single text. In this way, various writing forms can be absorbed by students gradually so that they can cope with passages in similar form with ease. In one word, form schema if activated timely can contribute greatly to students' reading comprehension.

\section{Strategies to Motivate Schema Theory in College English Reading Classes}

According to schema theory, students are supposed to be equipped with two necessary elements if they are capable to comprehend the text. The first element is that students are equipped with relevant schema related to the given text. And the other is they are supposed to manage to activate these existing schemas and apply them into reading. Hence, how to enhance the effect of students' reading comprehension by employing schema theory is to be introduced in a all-round way in this section.

\subsection{Establishing Abundant Schema Network}

'The key point of schema theory is that students always connect their existing knowledge with new things whenever comprehending new things. Obviously, students with more knowledge previously are considered more capable to comprehend new reading materials.

As we all know, college English reading is a comprehensive learning process. Students are required to read extensively. Nevertheless, it often gives rise to the situation where students have no according schema to apply when doing reading comprehension. In this way, enriching students' 
schema is becoming urgent.

Therefore, when teaching reading, teachers are suggested to introduce abundant background information combining topics appeared in every single unit to broaden students' horizon and further enrich schemas in students' minds. In this way, the schema in students' brain is becoming increasingly abundant day by day so that students can employ them automatically to comprehend the given reading materials efficiently.

\subsection{Activating Students' Existing Schemas}

When students are reading, specific schema will be activated accordingly if some similar words or conceptions related to any part of this schema come out. In college English reading teaching, teachers are suggested to adequately motivate all schemas in students' mind to achieve effective comprehension at full length.

Taking a text in College English named 'How to Improve Your Study Habits' as an example, the key point of comprehending this passage lies in activating students' existing schema about study habits. After activating the schema, students can understand the content of the text more easily.

\subsection{Helping Students to Establish New Schemas}

Due to the deficiency of student' English background information, it often comes to the case that there is no schema for students to employ when they are reading a certain materials. At this moment, establishing new schemas are becoming undoubtedly urgent for students to interpret reading materials. For instance, before explaining the passage 'A Day's Wait', teachers are suggested to make students have a basic understanding of Hemingway first, his life, his works as well as his influence to America even the world. After having a basic idea of these information, students can comprehend the thesis of this passage more easily.

\section{Conclusion}

Schema is a guide for us to teach English reading classes. It requires teachers to make adequate preparations for teaching, especially teachers themselves to have enough knowledge and full understanding of students. Teachers can use different methods to activate students 'existing schemata before reading, during reading, and after reading, or help students to build new schemata according to different teaching conditions, thus improving students' reading ability.

\section{Acknowledgement}

Fund: Shaanxi University of Traditional Chinese Medicine Research Fund; Issue number: 2016RW15.

\section{References}

[1] Carrel P.L. Schema Theory and ESL Reading Pedagogy [J]. TESOL Quarterly. 1983.

[2] Liu Yu-hui, Zhu Li-rong, Nian Yue. Application of Schema Theory in Teaching College English Reading [J]. Canadian Social Science. 2010.

[3] Goodman K.S. Psycholinguistic universals in the reading process. In The Psychology of Second Language Learning. Cambridge: Cambridge University Press. 1971.

[4] Rumelhart Schemata. The building blocks of cognition in the oretical issues in reading comprehension. Hillsdale: N, J. Erlbaum. 1980.

[5] Yanxia Shen. An Exploration of Schema Theory in Intensive Reading [J]. 2008. 